\title{
CONSERVAR É PRECISO: UMA AVALIAÇÃO PRELIMINAR
}

\author{
Rosemeri Carvalho Marenzi ${ }^{1}$ \\ Laura Piatto ${ }^{2}$ \\ Renata Muniz Ventura ${ }^{3}$ \\ Katiuscia Wilhelm Kangerski ${ }^{4}$
}

RESUMO: O Projeto "Conservar é Preciso" iniciou em 2000, de uma parceria entre a Universidade do Vale do Itajaí e a Fundação Praia Vermelha de Conservação da Natureza objetivando a conservação da Morraria da Praia Vermelha, Penha, SC. Atende escolas da região, adotando dinâmicas, apresentações e trilha interpretativa, sendo destacados aspectos do ecossistema, suas funções, inter-relações e os problemas e ameaças incidentes. Este Projeto já atendeu em torno de 5000 participantes e passou por um sistema de avaliação, sendo verificado que, mesmo atuando pontualmente, contribui com o processo de educação ambiental por meio de fatores cognitivos e afetivos.

Palavras-Chave: Educação Ambiental; Conservação; Floresta Atlântica.

\footnotetext{
${ }^{1}$ Doutora, professora e pesquisadora do Laboratório de Planejamento e Manejo de Unidades de Conservação da Universidade do Vale do Itajaí. E-mail: merimarenzi@univali.br.

${ }^{2}$ Oceanógrafa, ex bolsista de Extensão do Laboratório de Planejamento e Manejo de Unidades de Conservação da Universidade do Vale do Itajaí. E-mail: Ipiatto@yahoo.com.br.

${ }^{3}$ Bióloga, ex bolsista de Extensão do Laboratório de Planejamento e Manejo de Unidades de Conservação da Universidade do Vale do Itajaí. E-mail: naty.red@ibest.com.br.

${ }^{4}$ Diretora Geral da Fundação Praia Vermelha de Conservação da Natureza.

E-mail: katiuscia_ea@hotmail.com.
} 


\section{INTRODUÇÃO}

A beleza cênica, a variedade de ecossistemas e a riqueza dos recursos naturais na zona costeira brasileira atraíram e ainda estão incentivando diversas formas de ocupação. Esta realidade tem como consequência a perda da paisagem natural e a fragmentação de habitats, cujos remanescentes florestais nem sempre conseguem manter a diversidade original, resultando na ameaça de extinção dos componentes bióticos. Essa descaracterização também reflete em mudanças socioambientais, desvalorizando a identidade cultural local.

A Morraria da Praia Vermelha, localizada em Penha, SC, constitui uma das últimas reservas representativas da Floresta Atlântica no litoral centro-norte catarinense, compondo expressiva paisagem costeira e contendo relevante biodiversidade. No entanto, frente à pressão ocupacional e o uso inadequado dos recursos, sua integridade encontra-se ameaçada.

O "Conservar é Preciso" inicialmente buscou a participação espontânea da comunidade por acreditar que deva haver um envolvimento das pessoas, mesmo com diferentes interesses, em um consenso que resulte na conservação ambiental. Assim, houve a realização de um workshop para, a partir deste, encontrar medidas e soluções conjuntas almejando a proteção da Morrraria da Praia Vermelha.

A realização deste workshop se deu no final de 1998 no Núcleo de Penha da Universidade do Vale do Itajaí (UNIVALI), e a partir da sua realização houve legitimidade em um processo de mobilização social que culminou, em 1999, na criação da Fundação Praia Vermelha de Conservação da Natureza (Pra ver Natureza), organização de direito privado, sem fins lucrativos, que visa a proteção da Morraria da Praia Vermelha. Em uma parceria entre a ONG e a UNIVALI, o Projeto "Conservar é Preciso", passou a ser oficialmente desenvolvido a partir do ano 2000.

Este Projeto iniciou objetivando adotar medidas de conservação, como reflexo da percepção de que para minimizar os impactos negativos das ações antrópicas se faz necessária a integração da comunidade no processo de sensibilização e de conscientização, reconstruindo seus hábitos culturais de convívio com a natureza. Atualmente, o Projeto objetiva promover mudança de percepção e atitudes quanto à conservação da Floresta Atlântica, utilizando como laboratório de vivência a Morraria da Praia Vermelha, Penha, SC.

Especificamente, desenvolve atividades de sensibilização ambiental pontual a atores da rede escolar regional, extensiva a atores da rede escolar do município de Penha, presta atendimento ao Programa de Visita da UNIVALI e atua mobilizando e sensibilizando a comunidade e turistas no processo de conservação dos ambientes de Floresta Atlântica e da Morraria da Praia Vermelha, por meio de ações eventuais. 
Este trabalho visa relatar as experiências desenvolvidas durante um ano de atividade do referido projeto, enfocado nas Ações de Educação Ambiental na Rede Escolar Regional e apresentando resultados obtidos de março a dezembro de 2007.

\section{METODOLOGIA}

Este Projeto foi desenvolvido através de processos contínuos de atendimento à rede escolar da região centro-norte catarinense. Após passar por uma avaliação (BARRETO, 2005), foi constatada a aplicação de uma metodologia que utiliza mecanismos cognitivos (palestra) e afetivos (dinâmica e vivência em trilha), porém atuando de maneira pontual. Portanto, para uma atuação mais efetiva, o Projeto idealizou mais encontros e interferências em grupos específicos, criando o programa "Conservar Pra Ver Natureza". Neste, a Morraria da Praia Vermelha também é utilizada como Laboratório de Vivências, mas além de despertar para a valorização da Floresta Atlântica, também apresenta um contexto social pela história, enaltecendo a cultura local.

No entanto, mesmo oferecendo a opção de uma atuação mais extensiva (série de encontros), em 2007 o Projeto atuou da forma tradicional (encontro pontual - ETAPAS 1 e 2), mas sempre buscando sensibilizar a comunidade para as coisas da natureza e para a melhoria da estrutura da sociedade por considerarmos que é preciso que o indivíduo perceba o ambiente e o seu relacionamento com o mesmo, sua capacidade de transformá-lo e modificá-lo e a possibilidade de conservá-lo e recuperá-lo.

Este trabalho descreve a metodologia do Projeto com base em suas ações de 2007, descritas a seguir.

\section{AÇÕES DE EDUCAÇÃO AMBIENTAL NA REDE ESCOLAR REGIONAL - CONSERVAR PONTUAL}

ETAPA 1 - Conhecimento da Importância da biodiversidade da Floresta Atlântica, destacando a Morraria da Praia Vermelha - Intervenção 1.

Foi ministrada palestra com a ilustração de slides de animais e de plantas típicos do local, sendo destacadas as funções e inter-relações de algumas espécies e os problemas decorrentes do uso e comportamento inadequados.

Considerando que "a arte, a educação psicofísica e as ciências do ambiente contribuem com diferentes leituras, compreensão e expressão do mundo, caracterizando-se como áreas específicas complementares e sugerindo uma unificação para a percepção do todo" (CRIVELLARO et al., 2001), os alunos foram incentivados a vivenciar as informações obtidas na palestra através da criação de desenhos com a temática "de que forma desejaria encontrar a Floresta Atlântica no futuro", bem como através de dinâmicas de grupo preparadas conforme a faixa etária. Estas atividades 
propiciaram desenhos criativos, além de ricos momentos de sensibilização coletiva.

ETAPA 2 - Interação com o ambiente local, percepção das atitudes em relação à flora e a fauna silvestre, e uso dos recursos hídricos. Intervenção 2.

Após a palestra, os participantes vivenciaram um ambiente natural por meio de caminhada em uma trilha na Morraria da Praia Vermelha, em propriedade particular, tendo sido autorizado o uso, uma vez o traçado já aberto. Para preparo na trilha foram desenvolvidas dinâmicas de sensibilização, adaptada a cada grupo participante, objetivando propiciar uma maior interação com o ambiente.

$\mathrm{Na}$ trilha foram destacados aspectos da paisagem, dos ecossistemas e dos fatores de interação, relacionados à importância da biodiversidade e dos recursos hídricos, bem como a redução de espécies decorrentes de atividades predatórias e as consequências disso para a qualidade d'água. $\mathrm{O}$ estudo da paisagem proporciona um instrumento para compreender os fenômenos que atuam como consequência da complexa interação entre homem e natureza para conscientização da fragilidade dos equilíbrios ecológicos e da responsabilidade humana na manutenção dos mesmos (VILA, 1999).

\section{AÇÕES DE SENSIBILIZAÇÃO AMBIENTAL A COMUNIDADE E VERANISTAS}

Foram desenvolvidas atividades de sensibilização ambiental ao longo do ano, como participações em eventos para divulgação de trabalho científico, campanhas educativas e programas de rádio.

\section{DA ANÁLISE DESTE TRABALHO}

Para acompanhamento das atividades de 2007, por meio de formulário respondido pelos responsáveis de cada grupo, foram obtidas informações de todos os grupos atendidos onde também foi possível apresentar perguntas abertas e fechadas sobre Avaliação do Projeto "Conservar é Preciso". Em complemento, uma avaliação feita pelo bolsista responsável pelas atividades também foi registrada.

Somado à análise deste formulário, este trabalho contou com a metodologia da observação participante cujos dados foram obtidos por meio de registro dos bolsistas em "diário de campo", já utilizado em anos anteriores.

\section{RESULTADOS E DISCUSSÕES}

O Projeto Conservar é Preciso atuou no ano de 2007 com atividades inicadas no mês de março, agendadas por meio do "Programa de Visistas" da UNIVALI ou, diretamente, através do contato com a direção de cada escola interessada em participar. 
Durante esse período, foram atendidos 400 estudantes de 11 escolas dos municípios de Penha, Itajaí, Navegantes e Piçarras, e 47 estudantes da UNIVALI, Campus de Itajaí.

\section{ANÁLISE PELOS PARTICIPANTES}

Das doze instituições de ensino atendidas, seis (50\%) participaram da "Avaliação do Projeto", sendo observado que a forma de conhecimento sobre o mesmo ocorreu de diversas formas: divulgação por folheto (folders), site da ONG parceira (Pra Ver Natureza) e Secretaria de Educação. Nenhum dos participantes informou conhecer o Projeto por meio da página da UNIVALI/ Programa de Visita. Este fato denota que esta forma de divulgação não está tendo a repercussão desejada. Ainda, no espaço reservado para sugestões ao Projeto, um dos participantes aproveitou para registrar que "achei um pouco confusa as informações no site da UNIVALI quanto ao agendamento e para o link" (anotação de um participante). Portanto, é possível perceber a necessidade de aprimoramento deste instrumento de divulgação.

Outro questionamento se deu em relação à "dificuldade de meio de transporte ao Projeto", uma vez que os participantes devem se deslocar da escola à UNIVALI Núcleo Penha, onde são feitas as palestras, e deste, à trilha na localidade São Roque, onde se situa parte da Morraria da Praia Vermelha (2 $\mathrm{km})$. Um dos participantes, por haver agendado via "Programa de Visita", não soube da necessidade de deslocamento, por isto a bolsista se dirigiu à escola para a palestra, mas o grupo não participou da segunda parte do Projeto, em trilha. Dos outros participantes da avaliação, três (50\%) afirmaram não existir dificuldade e dois (33\%) afirmaram existir.

Estes últimos pertencem a escolas do município de Penha. Após a avaliação, as bolsistas do Projeto procuraram a Secretaria de Educação, onde foi providenciado que o transporte escolar destinaria um dia da semana, em período de não uso, para acesso ao Projeto. A partir daí, o agendamento de escolas de Penha aumentaram significativamente.

Quando questionados sobre "O que achou do Projeto", em uma escala de ruim, regular, bom e ótimo, todos os participantes (100\%) avaliaram em ótimo, sendo que não houve anotações no item "O que não gostou do Projeto". Em relação ao "Que mais gostou", quatro participantes $(67 \%)$ apontaram a trilha, dois $(33 \%)$ se referiram também a palestra e um $(17 \%)$ destacou a dinâmica realizada na abertura da palestra. A atividade em trilha também foi percebida com destaque na avaliação de Barreto (2005).

Em relação à questão "Pretende participar novamente do Projeto", todos (100\%) afirmaram que sim. Este fato denota a satisfação dos mesmos em participar das atividades do "Conservar é Preciso", possivelmente decorrente também da percepção de reflexo de prazer e de resultados alcançados relacionados aos componentes de cada grupo. 
Também se buscou entender "Quais os objetivos em participar do Projeto", sendo transcritas todas as respostas:

- "Conscientizar os alunos para preservar mata, enriquecendo, assim, minhas aulas";

- "Desenvolver a consciência ecológica fazendo-os participarem de movimentos de proteção ecológica";

- "Conscientizar os alunos de quanto é preciso preservar o meio ambiente";

- "Que as crianças reconheçam e valorizem a biodiversidade do seu espaço";

- "Entrar em contato com a natureza";

- "Preservar o meio ambiente e o contato nosso com a mata, ou seja, com o meio".

As respostas se mostraram de acordo com a ideologia do Projeto: promover mudança de percepção e atitudes quanto à conservação da Floresta Atlântica. Podemos observar que a primeira resposta relacionou o interesse em enriquecer suas atividades escolares, o que pode caracterizar o Projeto como parte de um processo. A segunda resposta associa seu objetivo à expectativa de sensibilizar seus alunos buscando maior atitude e as três $(50 \%)$ últimas afirmações objetivaram o contato com a natureza (espaço, meio, mata), o que denota a importância da atividade em trilha.

Por último, ressalta-se que as palavras conscientização, reconhecimento e valorização foram utilizadas, sendo esperado que os responsáveis pelos grupos estejam compreendendo que tudo isto está associado ao desenvolvimento do senso crítico, proposta da educação ambiental. Para Sauvé et al (2000), o pensamento crítico é uma atividade positiva e construtiva que permite compreender melhor as realidades e os problemas ambientais, para adotar soluções mais apropriadas e avaliar as ações e projetos com mais acerto, bem como criar grandes oportunidades para desenvolver e estreitar vínculos entre a escola e a comunidade. Também Sato (1994) afirma que, apesar de não existir uma técnica especial para a educação ambiental, é recomendável a promoção de alternativas aos problemas ambientais, discutindo um gerenciamento adequado à realidade, e o envolvimento da comunidade e experiências pessoais dos alunos.

\section{ANÁLISE PELOS EXECUTORES}

Em posse do "diário de campo" e do acompanhamento nas atividades desenvolvidas foram listados aspectos observados em relação ao "Conservar é Preciso" (Quadro 1). 
Quadro 1: Observação participante relacionando pontos positivos e negativos.

\begin{tabular}{|l|c|c|}
\hline \multicolumn{1}{|c|}{ ANOTAÇÕES DO "DIÁRIO DE CAMPO" } & $\begin{array}{c}\text { PONTOS } \\
\text { POSITIVOS }\end{array}$ & $\begin{array}{c}\text { PONTOS } \\
\text { NEGTIVOS }\end{array}$ \\
\hline Expressão de satisfação e excitação dos participantes. & $\mathrm{X}$ & \\
\hline $\begin{array}{l}\text { As atividades de maior envolvimento e interesse ocorrem durante o } \\
\text { percurso da trilha. }\end{array}$ & $\mathrm{X}$ & \\
\hline $\begin{array}{l}\text { Os participantes manifestam empolgação devido o conhecimento sobre } \\
\text { o assunto, principalmente sobre aves. }\end{array}$ & $\mathrm{X}$ & \\
\hline $\begin{array}{l}\text { Os participantes que mostram maior conhecimento sobre aves são } \\
\text { moradores locais. }\end{array}$ & $\mathrm{X}$ & \\
\hline $\begin{array}{l}\text { A mudança de disposição das carteiras escolares durante a palestra } \\
\text { motiva e provoca maior interesse e atenção. }\end{array}$ & $\mathrm{X}$ & \\
\hline $\begin{array}{l}\text { As dinâmicas de vivência são percebidas no início de forma } \\
\text { relativamente tímida, independente se a escola é particular ou pública. }\end{array}$ & & \\
\hline $\begin{array}{l}\text { As dinâmicas de vivência são percebidas com malícia pelos } \\
\text { adolescentes. }\end{array}$ & & \\
\hline $\begin{array}{l}\text { Os(as) educadores(as) normalmente encontram-se motivados e } \\
\text { interessados em participar. }\end{array}$ & $\mathrm{X}$ & \\
\hline $\begin{array}{l}\text { Os(as) educadores(as) desmotivados afetam a participação de seus } \\
\text { alunos. }\end{array}$ & & $\mathrm{X}$ \\
\hline $\begin{array}{l}\text { Os(as) educadores(as) normalmente demonstram interesse em retornar } \\
\text { com novas turmas escolares. }\end{array}$ & $\mathrm{X}$ & $\mathrm{X}$ \\
\hline $\begin{array}{l}\text { Quanto menor o grupo de pessoas na trilha melhor a desenvoltura do } \\
\text { projeto. }\end{array}$ & & \\
\hline $\begin{array}{l}\text { O tempo disponibilizado para as atividades do projeto, por algumas } \\
\text { escolas, reduz a qualidade do mesmo. }\end{array}$ & & \\
\hline $\begin{array}{l}\text { A falta de manutenção da trilha prejudica o envolvimento dos } \\
\text { participantes }\end{array}$ & & $\mathrm{X}$ \\
\hline O uso de data-show melhora a qualidade da palestra & & \\
\hline
\end{tabular}

Fonte: Adaptada de Barreto (2005)

As carteiras escolares geralmente são dispostas em fileiras, porém durante a palestra, muda-se a disposição para um círculo, "permitindo igualdade de condições de espaço, visão, audição e comunicação entre todos" (CRIVELLARO et al., 2001). Isso motiva e provoca maior interesse e atenção no tema abordado.

Pode-se ressaltar que a empolgação e interesse surgem principalmente quando os participantes se encontram fora de sala de aula, o envolvimento torna-se visível consequentemente com a manifestação de conhecimento sobre o local e os animais que ali habitam. Dias (1994) afirma que só é possível uma criança gostar de ciência trabalhando com o ambiente que a cerca, o local onde ela está inserida e através da prática.

Os participantes que mostram maior conhecimento sobre aves são moradores locais, podendo ser resultado de atividade de caça por esporte ou até mesmo como maneira de subsistência. Bettega (2002) comenta que esta atividade parece estar relacionada aos aspectos da cultura e costumes. Adams (2000) reforça a idéia citando que a caça na Floresta Atlântica é bastante apreciada e praticada tanto por moradores locais como por caçadores que vêm 
de fora. Especificamente na Morraria da Praia Vermelha, Marenzi (2004) comprova este fato.

As diversas dinâmicas oferecidas aos participantes facilitam a "relação entre coletividade e singularidade, favorecendo 0 autoconhecimento e 0 conhecimento do outro. É por meio desse autoconhecimento que nos valorizamos, resgatamos nossa autoestima, construímos nossa cidadania e nos tornamos capazes de conviver e auxiliar os outros. Esta valorização tende a diminuir a competitividade, pois estimula valores cooperativos e solidários" (CRIVELLARO et al., 2001). É esperado, portanto, que o Projeto possa contribuir neste sentido.

No início das dinâmicas, verificou-se um pouco de timidez nas crianças e malícia nos adolescentes, características que são normais nessas faixas etárias. Entretanto, logo começaram a se envolver e desenvolver as atividades sem problemas, inclusive alguns deles participando ativamente, ensinando alguma dinâmica conhecida, e refletindo a percepção e o envolvimento com o lugar no qual se encontram. Baseado neste fato, Del Rio (1996) afirma que a percepção é entendida como um processo mental de interação do indivíduo com o meio ambiente, que se dá através de mecanismos perceptivos propriamente ditos e, principalmente cognitivos, sendo que é a partir daí que o indivíduo toma consciência do mundo.

Os(as) educadores(as) que acompanham os seus alunos, mas que não demonstram interesse nas atividades, os afetam em demasia, e por consequência acabam intervindo de maneira negativa na desenvoltura da apresentação do projeto. Isso já foi observado por Valla e Stotz (1994, apud ANDRADE; LOUREIRO, 2001), lembrando que a avaliação a ser feita é também do processo educativo e não apenas do aluno. O suposto fracasso do aluno é parcialmente resultante do fracasso do professor, seja por sua formação deficiente, falta de capacitação ou por insatisfação; que, por sua vez, tem como causa primária o fracasso do sistema de ensino e a estrutura societária em que se insere.

Já os(as) educadores(as) que participam e demonstram interesse acabam estimulando ainda mais o envolvimento de seus alunos. Eles promovem a educação ambiental no processo pedagógico, preocupados em traçar uma perspectiva sustentável para as futuras gerações e o futuro do planeta como um todo. Como abordam Zakrzevski e Sato (2001), percebe-se que a formação de uma nova mentalidade exige ações que venham provocar mudanças nas abordagens que as diversas ciências dão no ensino formal.

\section{Conclusões}

Ao longo de todos os anos de "Projeto Conservar é Preciso", este atuou por meio de duas linhas, sendo uma voltada ao fator cognitivo, por meio de informações, e outra ao emocional, por meio de vivências (trilha). Desenvolveu ações também voltadas à comunidade, como entrevistas em rádios, TV e participação e apresentação em eventos científicos, os quais não foram Revbea, Rio Grande, V. 8, № 1:131-140, 2013. 
analisadas neste trabalho. Portanto, de maneira geral, buscou impelir ao seu público a concretização de novos valores e percepções a serem redescobertos e despertados em relação à natureza.

Em 2007 o Projeto atendeu a 447 estudantes de quatro municípios da região centro-norte catarinense, sendo que, após as duas formas de análise realizadas (participantes e executores do Projeto), foi possível verificar que o mesmo está satisfazendo às expectativas e aos interesses de seus participantes. No entanto, algumas alterações devem ser ajustadas para maior eficiência do Projeto, principalmente voltada a aprimorar o sistema de divulgação e de agendamento do "Programa de Visita".

Também foi possível perceber que a atividade de trilha provoca satisfação e vai ao encontro dos objetivos do Projeto e de seus participantes. Portanto, a mesma deve ser estimulada no sentido de enriquecimento do "Conservar é Preciso".

As duas formas de análise mostraram serem ferramentas importantes na avaliação do Projeto, devendo continuar sendo utilizadas como forma de retroalimentá-lo e torná-lo mais eficiente aos seus propósitos.

Considerando que a educação ambiental é resultado de um processo lento, que deve envolver a comunidade e as oportunidades de transformação social, é possível concluir que o Projeto possa estar contribuindo na proteção da Floresta Atlântica, e mais especialmente da Morraria da Praia Vermelha, provocando mudança de atitudes e formando agentes multiplicadores na conservação do meio ambiente.

\section{REFERÊNCIAS}

ADAMS, C. Caiçaras na Mata Atlântica: pesquisa científica versus planejamento e gestão ambiental. São Paulo: Annablume: FAPESP, 2000.

ANDRADE, A.L.C.; LOUREIRO, C.F.B. Monitoramento e Avaliação de Projetos em Educação Ambiental: Uma Contribuição para o Desenvolvimento de Estratégias. In: SANTOS, J.E.; SATO, M. A contribuição da Educação Ambiental à esperança de Pandora. São Carlos: Rima, 2001.

BARRETO, M. B. Sistema de Avaliação para um projeto de educação ambiental. Trabalho de Conclusão de Curso (Graduação) - Centro de Ciências Tecnológicas da Terra e do Mar, Universidade do Vale do Itajaí, 2005.

BETTEGA, G.T. Ação antrópica sobre a Pipile jacutinga na área de Proteção Ambiental de Guaratuba. Trabalho de Conclusão de Curso. Universidade Tuiuti do Paraná, Curitiba, 2002.

CRIVELLARO, C.V.L.; MARTINEZ NETO, R,; RACHE, R.P. Ondas que te quero mar: educação ambiental para comunidades costeiras: Mentalidade Marítima: relato de uma experiência. Porto Alegre: Gestal/NEMA, 2001. 
DEL RIO, V. Cidade da mente, cidade real: Percepção Ambiental e Revitalização na Área Portuária do RJ. In: DEL RIO, V.; OLIVEIRA, L. Percepção Ambiental. A experiência brasileira. São Paulo: EDUSFCar,1996.

DIAS, G.F. Atividades interdisciplinares de Educação Ambiental. São Paulo: Global /Gaia, 1994.

MARENZI, R. C. Ecologia da paisagem da Morraria da Praia Vermelha (SC): Subsídio à conservação da biodiversidade de uma área costeira. 2004. Tese de Doutorado. Universidade Federal do Paraná. Setor de Ciências Agrárias, Universidade Federal do Paraná, Curitiba.

SATO, M. Educação Ambiental. Universidade Federal de São Carlos: apostila, 1994

SAUVÉ, L. ORELLANA, I.; QUALMAN, S. La Educación ambiental: una relación constructiva entre la escuela y la comunuidad. Bolívia: EDAMAZ Quebec, 2000.

VILA, R. P. Paisage y educación ambiental in Aplicación de los estudios de paisaje. Barcelona: Masson, 1999.

ZAKRZEVSKI, S.B.B.; SATO, M. Refletindo Sobre a Formação de Professores em Educação Ambiental. In: SANTOS, J.E.;SATO,M. A contribuição da Educação Ambiental à esperança de Pandora. São Carlos: Rima, 2001. 